born infants. Patent ductus arteriosus (PDA) and pharmacological PDA treatment may jeopardize blood flow to the mesenteric vascular bed and therefore, increase risk of NEC. The role of enteral feedings during treatment for PDA is still unclear. The goal is to identify the role of feeding prior to and during the PDA treatment in development of clinical NEC.

Methods: The medical charts of infants admitted to the Neonatal Intensive Care Unit with PDA were reviewed to identify demographic, clinical, laboratory data, feeding pattern, ECHO results, and treatment. Data was analyzed in respect to the NEC diagnosis.

Results: Among 105 infants diagnosed with PDA , 33 with gestational age less than 30 weeks were included in the analysis. Among those $42.2 \%$ were diagnosed with clinical NEC. No difference in gestational age (26.4+/-1.9 vs. $27.0+/-1.7$ weeks), birth weight $(967+/-314$ vs. $1008+/-336$ grams), gender, race/ethnicity, maternal steroid use, mode of delivery, umbilical arterial or venal line placement, and pressor use in respect to the NEC were recorded. Majority (78.6\% with NEC and $63.2 \%$ without, $\mathrm{P}>0.05$ ) were treated with PGI. Almost all of infants with NEC (90.9\%) and without $(85.7 \%)$ were not on enteral feeding prior to and during PDA treatment. We found no difference in preterm comorbidities but higher median duration of ventilation among infants who were diagnosed with NEC.

Conclusion: In very preterm infants with PDA, treatment with $\mathrm{PGI}$ and enteral feeding during treatment was not associated with development of NEC.

1185

\section{SEASONAL NATURE OF NEONATAL JAUNDICE}

\author{
M. Cerna ${ }^{1}$, L. Vitek², K. Mala ${ }^{1}$, R. Konickova ${ }^{2}$ \\ ${ }^{1}$ Institute for the Mother and Child Care, ${ }^{2} 1$ st \\ Medical Faculty, Charles University, \\ Prague, Czech Republic
}

Empirical neonatological experience suggests, that prevalence and degree of neonatal jaundice might be dependent on seasonal variation, mainly due to the sunshine duration. However, evidencebased data on this issue are scarce. Thus, the aim of this study was to provide analysis of differences in the incidence of neonatal hyperbilirubinemia and frequency of phototherapy during summer and winter time.

We compared two groups of consecutive healthy, term neonates without $\mathrm{AB} 0$ and/or Rh incompatibility born in June $(n=286)$ and December 2008 ( $n=$ $279)$, respectively.

Surprisingly, compared to winter time hyperbilirubinemia >205[U1] umol/l was higher in summer ( 27.5 vs $22.9 \%$, p-value $<0.05$ ). Simultaneously, the freqeuncy of phototherapy was higher during summer (14.3 vs $10.0 \%$, p-value < 0.05).

We did not observe any influence of sunshine on the incidence of hyperbilirubinemia of neonates. The main reason for even higher neonatal jaundice during summer month migh be a multifactorial cause of neonatal jaundice, which makes it persistent neonatological challenge.

\section{6}

\section{RISK ASSESSMENT IN NEWBORNS BASED ON THE WEIGHT/LENGTH RELATIONSHIP}

\author{
J.R.D. Bertagnon ${ }^{1}$, G. Kuraim¹, P. Colombo², \\ N.F. Novo ${ }^{2}$ \\ ${ }^{1}$ UNISA- CENEPES-H Grajau- O C Santa \\ Catarina, 'Pós Graduação Saúde Materno Infantil, \\ UNISA, São Paulo, Brazil
}

Objective: To check relationship between newborns (NB) classification based on weight/length index (I) and the weight/gestational age adequacy.

Method: A retrospective cross study by record assessment was carried out, where the NB weight (g) was divided by length $(\mathrm{cm})$ for all NB discharged from hospital from September to December, 2009 $(\mathrm{N}=566)$. The 10 and 90 percentiles of the indices distribution were calculated leading to the following classification: small index (SI) for NB below $54.8 \mathrm{~g} /$ $\mathrm{cm}$, large index (LI) for those over $75.8 \mathrm{~g} / \mathrm{cm}$ and average index $(\mathrm{Al})$ for the remaining NB. It was checked the relationship between these indices and the weight/gestational age adequacy with the following classifications: pre-term for gestational age (PTGA), small pre-term (SPTGA), appropriate term (ATGA) and large term (GTGA). There were no large pre-term or post-term NB. Major affections were related to the index and adequacy extracts.

Results: A significant association was found between SI with PTGA and SPTGA, between AI 
with ATGA and LI with LTGA ( $\left.X^{2}=652,39 p<0,001\right)$. Hypoglycemia (3.5\%) was associated both with SI and $\mathrm{LI}\left(\mathrm{X}^{2}=9,15 \mathrm{p}<0,01\right)$ and with o PTGA, SPTGA and LTGA $\left(X^{2}=11,99 p<0,007\right)$.The Respiratory Distress Syndrome $(0.5 \%)$ was associated with SI $\left(X^{2}=43,35 p<0,0001\right)$ and PTGA $\left(X^{2}=55,70\right.$ $p<0,0001)$. No association was found between jaundice $(15.2 \%)$ or Sepsis $(0.7 \%)$ and any of the extracts.

Conclusion: The weight/length index may represent a key contribution to the NB risk classification with sensitivity similar to that of the weight/gestational age adequacy, for the affections studied.

\section{7}

\section{OUTCOME OF PRETERM INFANTS WITH NECROTISING ENTEROCOLITIS OR SPONTANEOUS INTESTINAL PERFORATION REQUIRING LAPAROTOMY FROM A LEVEL III NICU}

K. $\operatorname{Tan}^{1}$, J. Vakayil-Francis ${ }^{1}$, C. Karyadiguna ${ }^{1}$, K. Bawden ${ }^{1}$, P. Ferguson ${ }^{2}$, A. Sehgal ${ }^{1}$

${ }^{1}$ Monash Newborn, ${ }^{2}$ Paediatric Surgery, Monash Medical Centre, Melbourne, VIC, Australia

Background: The NICU at Monash Newborn is part of an integrated perinatal centre, where infants requiring surgery can be treated in-house. Emergency surgery is often performed within our NICU. Preterm infants who require laparotomy for either spontaneous intestinal perforations (SIP) or perforated necrotising enterocolitis (pNEC) represent a group of infants with very high mortality (ranging from 20 to $50 \%$ ). The aim is to study the outcome of these infants from our centre over a 5-year period.

Method: Preterm infants (2004 to mid-2009) < 32 weeks gestation who had diagnoses of either SIP or pNEC were identified from our NICU database. $X$-Ray images and reports were re-assessed. A proforma was used to extract data for these infants.

Results: In total 21 infants were identified. Eleven infants had SIP while 10 had pNEC. The average age $( \pm S D)$ for surgery was $6.9( \pm 5.9)$ days for SIP and $33.1( \pm 19.6)$ days for $p N E C$ (t-test; $p=0.002)$ with overall age of $19.2( \pm 19.3)$ days. Overall mortality rate was $23.8 \%$ (18.2\% for SIP and $30 \%$ for pNEC). Median (IQR) length of stay (LOS) for all survivors was 109 (64 to 199) days, while SIP infants' LOS was 70 (38 to 199) days and pNEC infants' LOS was 143 (123 to 183) days. Three infants from the SIP group had grade III/IV IVH in SIP while 1 infant with pNEC had PVL.

Conclusions: The mortality rate from our centre is comparable to published outcomes. SIP presented with perforation at a significantly earlier age compared to pNEC.

\section{8}

\section{GESTATION, NOT RATE OF GROWTH IN VERY PRETERM BABIES, DETERMINES THE RISK OF RETINOPATHY OF PREMATURITY (ROP)}

V.S. Garikapati ${ }^{1}$, A. Kipioti ${ }^{2}$, M. Watkinson ${ }^{1}$

${ }^{1}$ Neonatal Unit, ${ }^{2}$ Department of Ophthalmology, Birmingham Heartlands Hospital, Birmingham, UK

Background: Poor post-natal weight gain in preterm babies has been identified as predicting severe ROP. Monitoring it to select babies at risk could reduce ophthalmological examinations.

Aim: To review the relationship between post-natal weight gain and ROP.

Methods: A review of 263 consecutive babies < 32 weeks and/ or $<1500 \mathrm{~g}$ in 2008-9. Growth was measured as time to regain birthweight and weight gain in $\mathrm{g} / \mathrm{kg} /$ day between days 21 and 42 . ROP screening and grading was in line with UK national guidance.

Results: Forty babies died. 54 were discharged before day 42: none developed severe ROP. 169 survivors had full data.

Overall $9(4.2 \%)$ of survivors needed treatment.

\begin{tabular}{|l|l|l|l|l|l|}
\hline $\begin{array}{l}\text { Stage of } \\
\text { ROP }\end{array}$ & $\begin{array}{l}\text { Num- } \\
\text { ber }\end{array}$ & $\begin{array}{l}\text { Gesta- } \\
\text { tion } \\
\text { (wks) } \\
\text { Mean } \\
\text { (SD) }\end{array}$ & $\begin{array}{l}\text { Birth } \\
\text { weight } \\
(\mathrm{g})\end{array}$ & $\begin{array}{l}\text { Days to } \\
\text { regain } \\
\text { birth } \\
\text { weight }\end{array}$ & $\begin{array}{l}\text { Weight } \\
\text { gain } \\
\text { days } \\
21-42 \\
\text { (g/Kg/day })\end{array}$ \\
\hline 0 & 103 & $\begin{array}{l}29.3 \\
(2.1)\end{array}$ & $\begin{array}{l}1188 \\
(288)\end{array}$ & $\begin{array}{l}14.0 \\
(5.5)\end{array}$ & $15.1(4.5)$ \\
\hline 1 & 31 & $\begin{array}{l}27.5 \\
(2.1)\end{array}$ & $\begin{array}{l}952 \\
(280)\end{array}$ & $\begin{array}{l}12.8 \\
(4.3)\end{array}$ & $12.9(4.9)$ \\
\hline 2 & 21 & $\begin{array}{l}27.6 \\
(2.4)\end{array}$ & $\begin{array}{l}1046 \\
(236)\end{array}$ & $\begin{array}{l}15.2 \\
(5.9)\end{array}$ & $12.6(5.6)$ \\
\hline 3 & 13 & $\begin{array}{l}26.8 \\
(2.2)\end{array}$ & $\begin{array}{l}875 \\
(272)\end{array}$ & $\begin{array}{l}13.4 \\
(5.8)\end{array}$ & $11.7(7.5)$ \\
\hline $\begin{array}{l}\text { Aggressive } \\
\text { posterior }\end{array}$ & 1 & 24.4 & 550 & & 13.1 \\
\hline
\end{tabular}

[Findings] 